\title{
El Jardín Botánico del Instituto Provincial de Murcia: pasado, presente y futuro
}

The botanical garden of the "Instituto Provincial de Segunda Enseñanza" in Murcia: past, present and future

\author{
José Pedro Marín Murcia ${ }^{1 *}$ \\ josepedro.marin@unir.net,https://orcid.org/0000-0002-7457-5769 \\ José Damián López Martínez** \\ damian@um.es, https://orcid.org/0000-0001-8922-1325 \\ LUISA LÓPEZ BANET** \\ /lopezbanet@um.es, https://orcid.org/0000-0002-1951-4242 \\ *Universidad Internacional de la Rioja, España \\ **Universidad de Murcia, España
}

\section{Resumen:}

El Jardín Botánico del que fue Instituto Provincial de Segunda Enseñanza de Murcia, centro educativo creado en 1837, es uno de los pocos jardines de los institutos históricos españoles que han sobrevivido hasta nuestros días. En su momento este espacio educativo fue considerado como uno de los mejores del país y todavía conserva algunos de los ejemplares que sirvieron para la enseñanza de la botánica. A lo largo del siglo XIX y principios del XX los catedráticos de Historia Natural y Agricultura destacaron por su actividad ligada al desarrollo de los respectivos gabinetes de esas materias, atesorando excelentes colecciones de plantas y un valioso material científico-pedagógico.

En la actualidad forma parte de un parque público donde se desarrollan actividades que distan mucho de la función esencial-

\begin{abstract}
:
The Botanical Garden located in what once was the Murcia "Instituto Provincial de Segunda Enseñanza", founded in 1837, is one of the few remaining gardens of the historical high schools of Spain. At that time, the school was considered to be one of the best in the country and it still keeps some of the specimens that were used to teach botany. During the nineteenth and early twentieth centuries professors of $\mathrm{Na}$ tural History and Agriculture developed the activity of their departments in connection with this space, giving way to an excellent collection of plants and a valuable set of scientific and teaching materials. Today the gardens are part of a public park where the activities carried out are very different from the teaching functions for which they were originally conceived, to the extent that the plants are even at risk.
\end{abstract}

1 Dirección para correspondencia (correspondence address):

José Pedro Marín Murcia. departamento de Didáctica de las Matemáticas y de las Ciencias Experimentales. Universidad Internacional de la Rioja. Av. de la Paz, 137. 26006, Logroño (La Rioja). 
mente didáctica para la que fue concebido, poniendo en riesgo incluso la conservación de su flora.

Este trabajo pretende dar a conocer la historia de este espacio educativo y la intrahistoria de las prácticas llevadas cabo en él en relación con la enseñanza de las ciencias y el profesorado implicado, así como salvaguardar el patrimonio de las instituciones educativas de la Región de Murcia.

\section{Palabras clave:}

Historia de la educación; patrimonio histórico-educativo; memoria educativa; historia de la enseñanza de las ciencias; enseñanza de la botánica.
This paper seeks to explore both the history of this educational space and the intrahistory of the activities carried out in it in relation to the teaching of sciences and the staff involved. It also aims to safeguard the heritage of the educational institutions of the Region of Murcia.

\section{Key words:}

History of education; historical-educational heritage; educational memory; history of teaching sciences; teaching of botany.

\section{Résumé:}

Le Jardin Botanique de I'ancien "Instituto Provincial de Segunda Enseñanza" de Murcie, créé en 1837, est l'un des rares jardins historiques des lycées espagnols qui ont survécu jusqu'à nos jours. À cette époque-là, cet espace éducatif a été considéré comme l'un des meilleurs du pays et il conserve toujours quelques-uns des spécimens qui ont été utilisés pour l'enseignement de la botanique. Tout au long du XIXe et début du XXe siècle, les professeurs d'Histoire Naturelle et d'Agriculture se sont distingués par leur activité liée au développement des cabinets respectifs, ce qui leur a permis d'obtenir d'excellentes collections de plantes et un précieux matériel scientifique-pédagogique.

Il fait partie, de nos jours, d'un parc public où se déroulent des activités qui s'éloignent beaucoup de la fonction essentiellement didactique pour laquelle il avait été conçu, et qui menacent même la conservation de la flore.

Cet article vise à faire connaître I'histoire de cet espace éducatif et I'histoire sociale des pratiques mises en œuvre sur place par rapport à l'enseignement des sciences et de ses enseignants concernés. Il vise aussi à sauvegarder le patrimoine des établissements d'enseignement dans la région de Murcie.

\section{Mots-clés:}

Histoire de l'éducation; patrimoine historique et éducatif; mémoire éducative; histoire de l'enseignement des sciences; enseignement de la botanique.

Fecha de recepción: 20-9-2016

Fecha de aceptación: 2-12-2016

\section{Introducción}

El Instituto Provincial de Segunda Enseñanza de Murcia fue creado en 1837, al año siguiente se ubicaba en un edificio anexo al Seminario de San Fulgencio, creado en 1592, que a finales del siglo XVIII y comienzos del XIX era fundamentalmente un centro universitario de formación de 
bachilleres en Derecho y Filosofía. Pero también se explicaban en Murcia Química, Mecánica, Delineación y Agricultura para la enseñanza de artesanos que auspiciaba la Sociedad Económica de Amigos del País de Murcia (Viñao, 1986). La cátedra de Agricultura fue ocupada por José Echegaray Lacosta (Segura, 1987), padre del que fue premio Nobel de Literatura en 1904 y alumno del instituto murciano hasta que finalizó los estudios de bachillerato en 1846, José Echegaray Eizaguirre (Sánchez, 2004).

Los espacios escolares nunca se han reducido estrictamente al espacio del aula puesto que son muchos los casos en los que cobraron especial relevancia los espacios no edificados. En la enseñanza secundaria, a pesar de que buena parte de los institutos creados en España a mitad del siglo XIX se ubicaron en conventos procedentes de la desamortización eclesiástica, o que otros ocuparan edificios universitarios y, por tanto, carecían o mostraban una clara insuficiencia de patios de deporte, de recreo, o de espacios para llevar a cabo enseñanzas prácticas relacionadas con la enseñanza de las ciencias de la naturaleza (Viñao, 2008), el Reglamento de 1845 para la ejecución del Plan de Estudios especificaba que los institutos debían tener un jardín botánico y un herbario dispuesto metódicamente (Gaceta de Madrid, 1845, p. 3). Gil de Zárate, Director General de Instrucción Pública desde 1846 a 1851 y autor principal del Plan Pidal de 1845, decía en 1855 "con marcado optimismo" que no había institutos que no dispusieran de cuanto requerían "las explicaciones de matemáticas, física, geografía e historia", y que muchos de ellos, añadía, poseían además un "jardín botánico", "regulares colecciones de historia natural" y, algunos, "preciosas bibliotecas" (Gil, 1855, pp. 68-69). Igualmente el plan de estudios de 1852 establecía que, como medios y recursos didácticos en los institutos, habría "gabinetes, laboratorios, jardines botánicos, instrumentos, máquinas, colecciones y cuanto sea necesario para la enseñanza de las ciencias" (Utande, 1964, p. 132). De esta forma el estudio de la botánica se reforzaba con la adquisición de locales limítrofes a los institutos, lugares donde se instalaba un jardín para llevar a cabo enseñanzas prácticas (Hernández, 2009).

En el marco de las investigaciones que se vienen realizando en el Centro de Estudios sobre la Memoria Educativa (CEME), de la Universidad de Murcia $^{2}$, nuestro trabajo pretende dar a conocer la historia de

2 Entre los últimos trabajos se ha realizado la tesis doctoral "El material científico para la enseñanza de la botánica en la Región de Murcia (1837-1939)" por José Pedro Ma- 
este espacio educativo, y con ello difundir la memoria y el patrimonio histórico-educativo de instituciones formativas de la región de Murcia (Viñao, 2010). También trata de mostrar la función educativa desarrollada en el Jardín Botánico a través de las prácticas llevadas cabo en relación con la enseñanza de las ciencias, una función que ha existido como algo inherente a estos jardines ya que por tradición se han considerado "museos vivos" por las plantas que atesoran, clasificadas y ordenadas conforme a criterios científicos, estéticos y educativos (García, 2013) lo que nos brinda nuevas perspectivas para profundizar en el conocimiento histórico de las concepciones y las prácticas educativas. Por último, trata de enfatizar en la necesaria educación patrimonial para salvaguardar y recuperar nuestro patrimonio histórico.

\section{Los orígenes del Jardín Botánico de Murcia}

Los terrenos utilizados para las prácticas de enseñanza de la botánica y agricultura de la cátedra auspiciada por la Sociedad Económica de Amigos del País de Murcia constituyen el inicio de lo que sería el origen del Jardín Botánico. La actividad de la cátedra con Echegaray se desarrolló en el huerto del extinguido convento de San Francisco, junto al Paseo del Malecón, paralelo al río Segura a su paso por la capital murciana. El 19 de octubre de 1835 la Sociedad Económica de Amigos del País de Murcia solicitaba al gobierno que le cedieran el Colegio de la Purísima Concepción y el huerto de San Francisco. El 20 de noviembre se concedió dicha cesión a condición de que la corporación pagara, por justa tasación, el correspondiente canon en favor de los acreedores del Estado respecto al mencionado huerto ${ }^{3}$. En esos terrenos se dieron lecciones prácticas a la vez que se procuraba la aclimatación de plantas y árboles traídos de América y otros países meridionales; asimismo se instruía en el manejo de algunos instrumentos de cultivo, no muy numerosos por la escasez de recursos destinados a esta enseñanza, y se difundían los últimos adelantos relacionados con la agricultura.

La cátedra de Agricultura se incorporó posteriormente al Instituto. Sin

rín Murcia, dirigida por los profesores José Mariano Bernal Martínez y José Damián López Martínez.

3 Archivo Real Sociedad Económica de Amigos del País de Murcia. Cesión a la Real Sociedad del edificio del suprimido colegio de la Purísima Concepción y del huerto contiguo. L069 C04 D02. 
que en su archivo figure noticia de la causa, dejó de llevarse a efecto la Real Orden que había dispuesto la cesión de la propiedad del huerto a dicha cátedra. Siguió a disposición del profesor Echegaray una pequeña parte del mismo, insuficiente para la cátedra, pese a que la enseñanza iba progresando y aumentaba la necesidad de espacios, mucho más si se tiene en cuenta que en este centro existía otra cátedra como la de Historia Natural (Hernández, 1983).

En una carta de Echegaray al ayuntamiento se refleja la precariedad de la dotación de la cátedra y también se nos informa sobre las actividades del científico en la Murcia de 1840 (Ruiz, 1983). El catedrático recordaba que, a pesar del escaso espacio de terreno que se destinó para los ensayos agronómicos, de carecer de un jardinero y de las vicisitudes que sufrió el jardín por el derribo del convento inmediato, se pudieron cultivar vegetales y se realizaron una serie de experiencias importantes. En el texto se destacan el cultivo de la caña dulce, del añil (Indigofera tinctoria) en estado de arbusto, de algodón para ver si era preferible a otros cultivos de la huerta, las experiencias para destruir los insectos que devoraban la alfalfa, la producción de seda a partir de gusano, criado con morera, de trigo y cebada de un mérito sobresaliente, y de una infinidad de plantas con aplicación a las artes y a la medicina. De los trabajos desarrollados se presentaron memorias a algunas sociedades científicas siendo premiados algunos de ellos. También en la prensa se publicaron artículos de interés sobre temas relacionados con la agricultura (Echegaray, 1847).

Echegaray, en otra carta dirigida al Secretario de la Sociedad Económica de Amigos del País en 1846, presentaba unas muestras de caña de azúcar cultivadas en el huerto y recordaba que una comisión de la corporación le pedía un informe sobre el cultivo de este vegetal en la provincia. En dicho informe se daba una idea de lo que se podía producir de acuerdo con las características climáticas de Murcia. Apuntaba también la necesidad de que hubiera un jardín de aclimatación para hacer ensayos de mayor envergadura ${ }^{4}$. Es lógico pensar que los estudios de Agricultura cesaron en 1848 cuando Echegaray consiguió el traslado a Madrid (López, 2001).

Según Rafael Verdú Payá, catedrático de Ciencias Naturales y director del instituto murciano, el huerto quedó finalmente vinculado a este centro

4 Archivo Real Sociedad Económica de Amigos del País de Murcia. Oficio del Sr. Echegaray. L080 C03 D04. 
educativo debido al tesón del claustro y especialmente a Echegaray, quien en defensa del espacio para las enseñanzas prácticas hizo saber al claustro que el Estado, como propietario del huerto del convento de San Francisco y edificios anejos, estaba dispuesto a anunciar su venta al público, circunstancia que de llevarse a cabo dificultaría en extremo la enseñanza de la asignatura (Verdú, 1958). El claustro acordó que esos terrenos no solo eran indispensables para la cátedra de Agricultura sino también para la de Historia Natural, por lo que se decidió actuar para que se cediera el huerto al Instituto. No obstante, el huerto estuvo a cargo de la Junta Provincial Agrícola desde 1849 hasta diciembre de 1863 (Hernández, 1983).

Tras la marcha de Echegaray a la Escuela Superior de Veterinaria de Madrid como catedrático de Agricultura aplicada a la Veterinaria, la actividad del Jardín Botánico quedó vinculada a las tareas de docencia e investigación del también catedrático de Historia Natural de este Instituto Ángel Guirao, quien ocupó la cátedra desde 1842 hasta su muerte en el curso 1889-90 (Segura, 1987). Guirao fue director del centro a partir de 1857, una época dorada llena de proyectos e inversiones. Era socio fundador y presidente en 1881 de la Sociedad Española de Historia Natural, hecho indicativo de su relevancia como científico, y mantuvo contactos con importantes botánicos a nivel internacional que utilizaron sus pliegos e información sobre plantas de la región de Murcia para realizar importantes aportaciones a la flora de la península Ibérica. La enseñanza de la asignatura impartida por este profesor se basaba en el Manual de Historia Natural, de Manuel de Galdo (1856), catedrático del Instituto de Noviciado (más tarde Cardenal Cisneros) de Madrid y en el Programa razonado de un curso de Historia Natural, de Sandalio de Pereda (1864), catedrático del Instituto San Isidro, también de Madrid. Los estudios prácticos se basaron en las constantes excursiones realizadas con sus discípulos por la huerta y por las sierras cercanas, según relataba Ricardo Codorniu (1909), en la utilización de su herbario, el Jardín, así como de un campo de cultivo costeado de su bolsillo (Instituto Provincial de Segunda Enseñanza de Murcia, 1859):

posee el Instituto un pequeño jardín botánico, establecido, costeado y sostenido por el que suscribe; y aunque no tiene herbario todavía, se suple con el numeroso que tiene el catedrático de la asignatura, que es uno de los más perfectamente determinados de España, por haber sido examinado y corregido por muchos de los principales botánicos de Europa. (p. 11) 
La intensa actividad naturalista y botánica de Guirao queda reflejada en la gran cantidad de especies herborizadas. En la actualidad sus pliegos de herbario se encuentran repartidos entre la Universidad de Coimbra, el Museo de Historia Natural de París y el Real Colegio Alfonso XII de San Lorenzo de El Escorial. En este último se conserva una colección con pliegos de 136 plantas de la región de Murcia, recolectadas entre los años 1844 y 1855 que forma parte del herbario M. P. Graells (Carrasco et al., 2001).

Durante el tiempo que el recinto del Jardín Botánico estuvo bajo la administración de la Junta Provincial de Agricultura se sacó a subasta pública la adjudicación de diversas obras de cantería y albañilería (Boletín Oficial de la Provincia de Murcia, 1859, p. 1). Sabemos que era usado como terreno de experimentación agrícola, como prueban los trabajos de Guirao con la aclimatación de trigo africano de la variedad chamorro enviada por el Ministerio de Fomento a la Junta de Agricultura de la Provincia de Murcia ${ }^{5}$. Otra de las actividades de la que tenemos constancia es la distribución de una gran porción de semillas y plantas de adorno procedentes del Jardín donde se aclimataban y se hacían ensayos agronómicos con semillas recibidas de otros lugares ${ }^{6}$.

Durante el curso 1860-1861, con motivo de la visita del Comisario del Rector de distrito, se planteó la conveniencia de establecer los estudios de Agricultura por su importancia para la provincia. En esa visita, el Rector de Valencia, José Pizcueta, volvía a recordar la importancia de implantar dichos estudios y poner a su disposición el Jardín que había pertenecido al Instituto hasta 1849 y que desde entonces estaba gestionado por la Junta Provincial de Agricultura. En una carta dirigida al profesor Guirao (Instituto Provincial de Segunda Enseñanza de Murcia, 1862), el Rector manifestaba que:

he visto que $\mathrm{V}$. S. posee un pequeño trozo para cultivar las plantas más precisas para las lecciones botánicas: parte del terreno que poseía el Instituto, cedido por el Gobierno a la Junta de Agricultura para sus ensayos, y que no

5 Archivo Real Sociedad Económica de Amigos del País de Murcia. Oficio de la Junta de Agricultura sobre ensayos con arroz africano llevados a cabo a petición del Ministro de Fomento, firmado por Ángel Guirao como secretario de la Junta, 14-10-1853. L088 C07 d05.

6 Archivo Real Sociedad Económica de Amigos del País de Murcia. Oficio de la Junta de Agricultura sobre ensayos de semillas de plantas de adorno firmado por Ángel Guirao como secretario de la Junta. 01-06-1858. L089 C01 D01. 
utiliza. V. S. debe volver a adquirir todo el terreno expresado, ampliar el cultivo botánico, y preparar lo demás para la cátedra de Agricultura que debe establecerse, y lecciones de la Normal. (p. 14)

\section{El Jardín Botánico para el Instituto}

En 1863 se procedió a la devolución del Jardín Botánico al Instituto. Una vez conseguido el terreno, bajo la actuación de Guirao funcionó a pleno rendimiento como campo de prácticas para la enseñanza de la Historia Natural y la Agricultura (López, 2001), aunque la inclusión de la Agricultura como asignatura del bachillerato no se produjo hasta 1876.

La Diputación Provincial de Murcia acordó el 30 de abril de 1862 la creación de una Escuela de Agricultura dependiente del Instituto, en la que se impartiría Botánica, Agricultura General, Horticultura, Química Aplicada a la agrimensura, Aritmética y Geometría con agrimensura y Nociones de contabilidad aplicada a la agricultura e industrias aplicadas (Hernández, 1983). El 9 de noviembre de 1869 el gobierno autorizó la creación provisional de dicha escuela. De este modo quedó establecida la carrera de Agrimensor, aunque tendría sólo siete años de vida.

Por medio de los exámenes realizados en 1873 de los peritos agrimensores, depositados en el Archivo Regional de Murcia ${ }^{7}$, disponemos de una detallada descripción del Jardín. Sus límites eran: a levante las posadas del Malecón, al mediodía el Paseo del Malecón con la puerta principal, a poniente un huerto particular y al norte el huerto de las monjas Isabelas y la calle del Mesón, donde había otra puerta de acceso. El alumno Francisco Alonso y Ruiz manifestaba (figura 1) que la finca tenía una cabida de:

72 áreas, 58 centiáreas y 75 decímetros equivalente a 5 tahúllas, 4 octavas y 17 brazas. De estas tahúllas la mitad está plantada de berenjenas, dos variedades de flores y el resto de barbecho y paseos. Conteniendo además tres moreras, cuatro palmeras, cuatro melocotoneros, un plátano, una magnolia, tres perales, once pereteros, ocho higueras, cuatro albaricoqueros, ocho granados, cuatro acacias, un níspero y veinte y seis cipreses.

7 Archivo Regional de Murcia. Expediente académico de Francisco Alonso Ruiz y Antonio Marín Martínez. IAX, 1397/23 y IAX, 1397/17. 
Otro alumno, Antonio Marín Martínez, indicaba en su ejercicio (figura 1) que de los parterres que tenía el jardín, dieciséis estaban destinados al cultivo de flores, otros dos a la agricultura del tomate y uno grande a la calabaza.
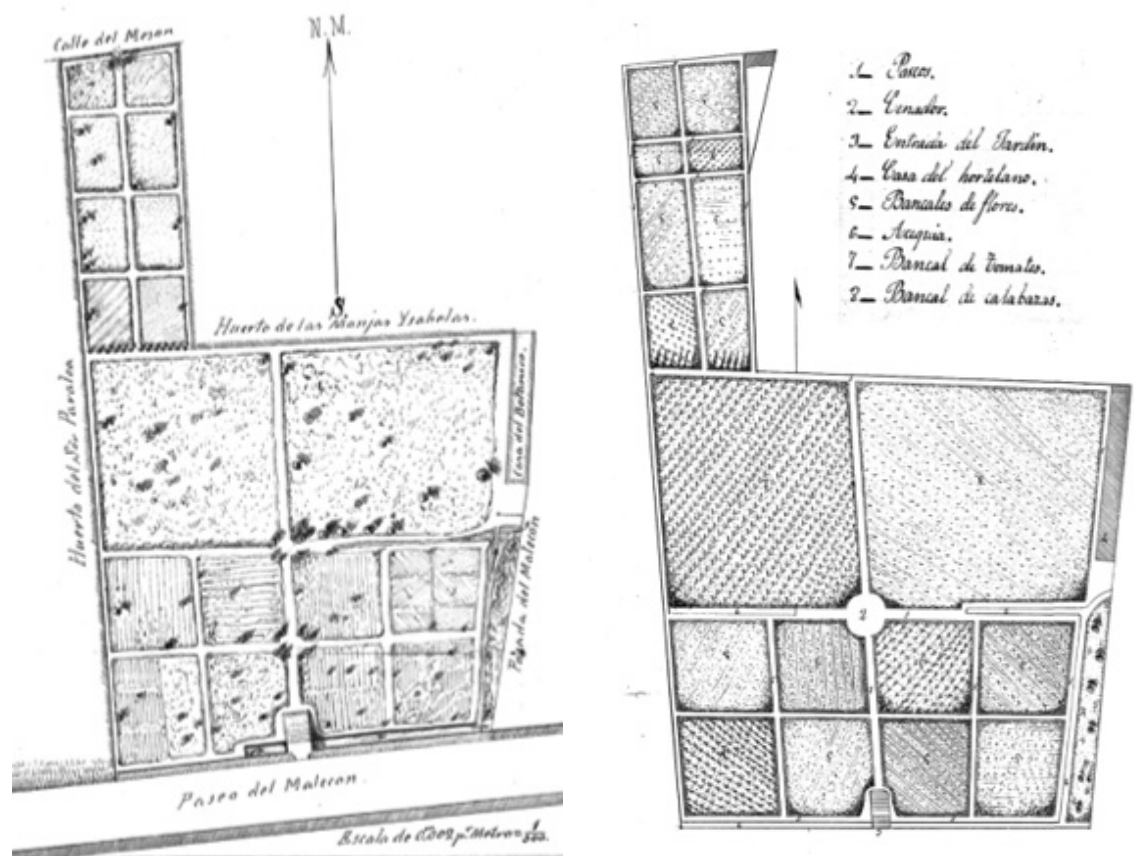

Figura 1. Plano del Jardín Botánico del Instituto de Murcia con la situación del arbolado y sus límites, y plano topográfico del mismo en el que se pueden observar los usos agrícolas de cada uno de los bancales en los que se dividía la superficie.

En la Memoria de la inauguración del curso académico 1883-84 se indicaba que el Jardín estaba formado por numerosas y preciadas especies remitidas por el Jardín Botánico de Valencia (Instituto Provincial de Segunda Enseñanza de Murcia, 1884):

especial atención del fomento del estado del Jardín Botánico nutrido de numerosas y preciadas especies remitidas por el Jardín Botánico de Valencia que de esta manera procura llenar la misión que le está encomendada, propagando cuanto se puede contribuir a ensanchar los límites de la enseñanza de la botánica en nuestro país y a cuyo centro debemos y tributamos sincera expresión de reconocimiento. (p. 10) 


\section{El Jardín Botánico de Murcia, uno de los más notables de los institutos españoles}

En 1887 se habían construido tres invernaderos, se compraron numerosas plantas y cincuenta tarjetones de zinc para su identificación. En 1890 se adquirió una partida de macetas de alfarería y un generador de vapor de plancha de cobre con un caballo de fuerza para alimentar un termosifón, además de una estufa inglesa con tres metros de chimenea para el invernadero de plantas tropicales (Instituto Provincial de Segunda Enseñanza de Murcia, 1887, p. 56; 1889, pp. 55-56; 1890, p. 5).

Las Memorias anuales del Instituto dan noticia de su reparación entre 1890 y 1891: "se fortaleció y decoró la escalera de entrada, aprovechando su emplazamiento sobre la acequia de La Arboleja para instalar en la bóveda un oportuno invernadero acuático". Durante el curso 1891-1892 se iniciaron reformas para levantar un umbráculo, indispensable para las plantas de invernadero durante el verano. Deteriorado el anterior, se sustituyó por uno de fábrica con diez columnas de fundición apoyado en un zócalo de sillería de $12 \mathrm{~m}$ de largo por $5 \mathrm{~m}$ de ancho, y en su cubierta de $13 \times 6 \mathrm{~m}$ con quince arcos de hierro en $\mathrm{T}$, forma china y circunvalada por crestería de zinc; también se recibió una colección de plantas del extranjero y ciento seis tarjetones metálicos con inscripciones. Según el secretario del centro, se realizaron importantes obras por lo que pasó "en pocos años a la condición de uno de los más notables, si no el que más, entre los de Instituto" (Instituto Provincial de Segunda Enseñanza de Murcia, 1891, p. 10; 1892, pp. 10 y 55)

Tras la muerte de Ángel Guirao le sucedió en la cátedra de Historia Natural Francisco Cánovas Cobeño. Cánovas fue uno de los grandes naturalistas que ha tenido la región de Murcia, realizando importantes aportaciones sobre la geología y paleontología del sureste peninsular (Delgado et al., 2010). Un año después de ocupar la cátedra editó su curso para las clases de Historia Natural siguiendo el criterio taxonómico de Candolle al considerar su clasificación más metódica y más al alcance de los alumnos por "estar en ella incluidos, con su orden relativo, los cuatro grupos de plantas que en la actualidad admiten los botánicos, a saber: fanerógamas en las cinco primeras clases, criptógamas y muscíneas en la sexta y las talofitas en la séptima" (Cánovas, 1891, p. 95). Cánovas tuvo gran interés en que el Instituto tuviera buenas colecciones de material científico, quedando constancia de ello por sus solicitudes 
al Jardín Botánico y al Museo de Ciencias Naturales de Madrid para que le enviaran ejemplares "a fin de aumentar las colecciones de este Instituto en beneficio de la enseñanza" ${ }^{8}$. En una carta manifestaba a Miguel Colmeiro, Director del Jardín Botánico de Madrid, que la falta de presupuesto le había "impedido el dar el catálogo de las plantas cultivadas en el Jardín, ni hacer en él algunas obras necesarias e indispensables" ${ }^{\prime \prime}$. Y le solicitaba que le remitiera una lista de las especies que deseaba tener en el Jardín Botánico. Según Carlos López, en la etapa de Cánovas al frente de la cátedra de Historia Natural (1891-1897) no hubo adquisiciones relevantes de material, pero recuerda que esta circunstancia quedó compensada con la donación al Instituto de sus valiosas colecciones científicas particulares (López, 2001).

El huerto del Jardín Botánico, bajo la dirección del profesor Cánovas, era un bellísimo jardín según informaba la prensa (Peñaflor, 1900, p. 1). También se ha recogido en la prensa posteriormente (Vázquez, 1960), comentarios de los trabajos realizados:

los profesores y alumnos ayudados por el inteligente y bondadoso jardinero Paco Asensi, iban poniendo a cada árbol, a cada planta, a cada arbusto y a cada rosal una visible y expresiva etiqueta, en latín y en castellano, que indicaba claramente, y con gruesos trazos el nombre y origen de la planta para que los estudiantes y el público que visitaba el ameno y apacible jardín tuvieran conocimiento de asignatura que estudiaban o de las plantas que veían. (p. 6)

Otra figura relevante relacionada con el tema que nos ocupa es la de Tomás Museros ${ }^{10}$, catedrático de Agricultura del Instituto desde 1877 a 1900. Durante los primeros años de su etapa en Murcia realizó una gran labor en la adquisición de colecciones, láminas e instrumental para el Gabinete de Agricultura (López, 2001). En este sentido, se adquirieron colecciones de cactus, modelos de frutas de cera, microscopios para observar granos, láminas de la Exposición Agrícola de París y ejemplares de semillas. La

8 Carta dirigida al Director del Museo de Ciencias Naturales, 25 de mayo de 1881. Archivo del Museo de Ciencias Naturales de Madrid. Ref. 263/19.

9 Carta dirigida al Director del Jardín Botánico de Madrid, 11 de febrero de 1894. Archivo del Real Jardín Botánico de Madrid. RJB01/0092/0003/0012.

10 Tomás Museros (i?-1901) fue catedrático del Instituto de Lorca a partir de 1867. Anteriormente ejerció en la Escuela Central de Agricultura, en el Instituto de Castellón y como director de una Escuela Práctica de Agricultura de esa provincia. 
Diputación Provincial de Murcia le comisionó en 1878 para la visita y estudio de las Exposiciones Agrícolas de Valladolid y la Universal de París.

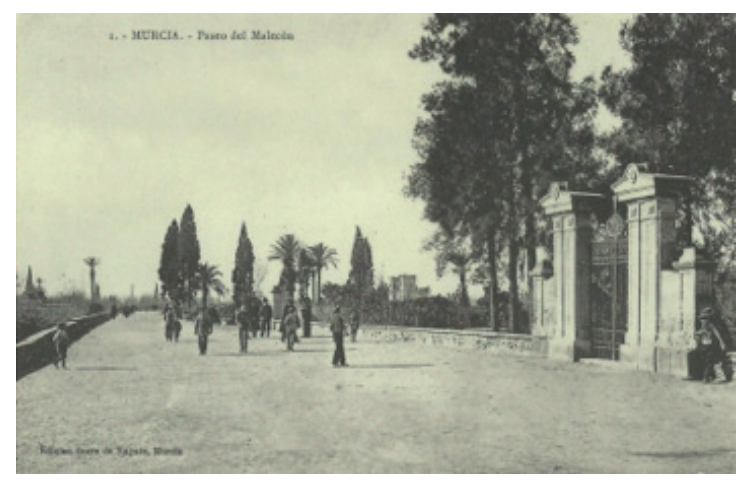

Figura 2. Postal del Paseo del Malecón y entrada al Jardín Botánico. Edición de Sucesores de Nogués. Pintura de Antonio Nicolás donde se ve un árbol del Jardín Botánico de ramas péndulas, quizás una morera y varios bancos.

(Harada-Giro, 1921, p. 21).

En 1883, además del citado material, existían tres cuadros con plantas forrajeras, doce plantas variadas, modelos agrícolas, una colección de cuadros de sistema de jardinería, de dibujos de máquinas aplicadas a la agricultura y sus industrias, un cuadro de dibujos iluminados representando los sistemas de irrigación y de drenaje, dos cuadros iluminados del cultivo de setas y otro de raíces alimenticias y hortalizas de Inglaterra y 38 clases de tierras de cultivo en frascos (Instituto Provincial de Segunda Enseñanza de Murcia, 1882, pp. 109-110).

La prensa (Vázquez, 1960) ha relatado cómo el profesor Museros daba lecciones prácticas a sus alumnos que:

siempre resultaban provechosas y agradables, porque se recibían en plena Naturaleza y con, un ambiente perfumado por las abundantes flores de incomparable belleza y bajo la sombra de sus numerosos y gigantescos árboles, entre los que se contaban también arbustos y plantas de las más raras y variadas especies. (p. 6)

Museros dividía su asignatura en dos partes: la primera comprendía la agricultura general, y la segunda la agricultura especial y la zootecnia. 
En sus lecciones ofrecía nociones sobre los órganos de las plantas: "si de los órganos vegetales pasamos a sus funciones, observaremos fenómenos tan importantes en la vida de las plantas que nos harán estimar cuanto debemos a esta ciencia" (Museros, 1880, p. 16). La asignatura trataba el desarrollo de las plantas y los tipos de suelos, su clasificación, conveniencias que unas y otras ofrecían para determinadas especies vegetales, así como las diferentes maneras de multiplicar las plantas, los tipos de abonos y la influencia de los elementos atmosféricos. Cuestiones que reflejan el tratamiento de la agricultura desde un punto de vista científico, en relación directa con el estudio del medio ambiente.

\section{El mejor momento del Jardín Botánico}

Tras una etapa de estancamiento y descenso en la incorporación de materiales se produce una reacción con el acceso a la dirección del centro del profesor Andrés Baquero Almansa. En este sentido, se obtuvo una colección de semillas procedentes del Jardín Botánico de Madrid y al año siguiente se recibió otra del Instituto Agronómico de la Moncloa. También se repararon y construyeron 338 tarjetones de zinc para el etiquetado de plantas, lo que da una idea del número de plantas que se pudieron reunir (Instituto General y Técnico de Murcia, 1907, p. 8; 1908, p. 57). Baquero manifestaba en el discurso de apertura del curso académico 1910-1911 (Instituto General y Técnico de Murcia, 1910) que:

en el Botánico, por ejemplo, se darán este año clases prácticas, utilizando aquel pabellón, construido ad hoc, y el variado surtido de plantas raras de aquel hermoso invernadero .... y no se tardará mucho en disponer asimismo de un pequeño campo de experimentación para Agricultura, que va anejo al grupo de Escuelas Graduadas del Barrio. (pp. 69-70)

El Jardín vivió esta época de esplendor utilizando estas mejoras en las enseñanzas de Historia Natural y de Agricultura, impartidas por los profesores Miguel Rivera Ruiz y Pedro Bernal. Durante el curso 1908-1909 se adquirió una serie de lupas. En 1909 un magnífico gabinete de anatomía comparada compuesto por 43 modelos, con lo que se enriquecía la clase práctica de botánica y de agricultura. En el curso 1911-1912 se completaron los modelos sobre la germinación de plantas monocoti- 
ledóneas (Instituto General y Técnico de Murcia, 1909, p. 51; 1910, p. 55; 1912, p. 53). El gabinete de Agricultura también tuvo una época de recuperación con la adquisición de nuevos materiales y la construcción de un campo de experimentación de cultivos durante el curso 1910-11 (Vidal y López, 1987). Se acometieron reformas de importancia con la construcción de un pabellón para las clases prácticas de botánica, y la instalación de un gran invernadero acondicionado para plantas de estufa (Instituto General y Técnico de Murcia, 1908, p. 12). Durante el curso 1912-1913 se continuó ampliando la colección de plantas con sus respectivas chapas de zinc (Instituto General y Técnico de Murcia, 1912, p. 53). Rafael Verdú apuntaba sobre estas mejoras que, además de dotar al Jardín con un modernísimo invernadero metálico y un umbráculo del mismo material, se repararon también todos sus desperfectos. Y se canalizaron las acequias que lo atravesaban, construyéndose un estanque para el cultivo de plantas acuáticas y un invernadero especial para las mismas, "algunas de las cuales, así como de las iniciales debidas a José Echegaray, aún perviven milagrosamente [aunque] por desgracia se han perdido en su gran mayoría" (Verdú, 1958, pp. 14-15). Existen gran cantidad de fotografías del Paseo del Malecón en las que se aprecian los ejemplares arbóreos (figuras 3 y 4).

Sabemos por la prensa periódica (Vergel, 1929) que no fue un jardín abierto al público a principios de siglo XX:

El Botánico, está exclusivamente reservado a los alumnos del Instituto en aquellos días en que la lección obligada es el estudio de la Naturaleza. Por ser de propiedad casi particular no puede disponerse de é1 y recrearse el público amante de estos lugares en las múltiples bellezas que encierra; pero acaso una gestión acertada y la garantía de una eficaz vigilancia pudieran conseguir su apertura al público y el acceso a él sin trabas durante el día. (p. 3) 


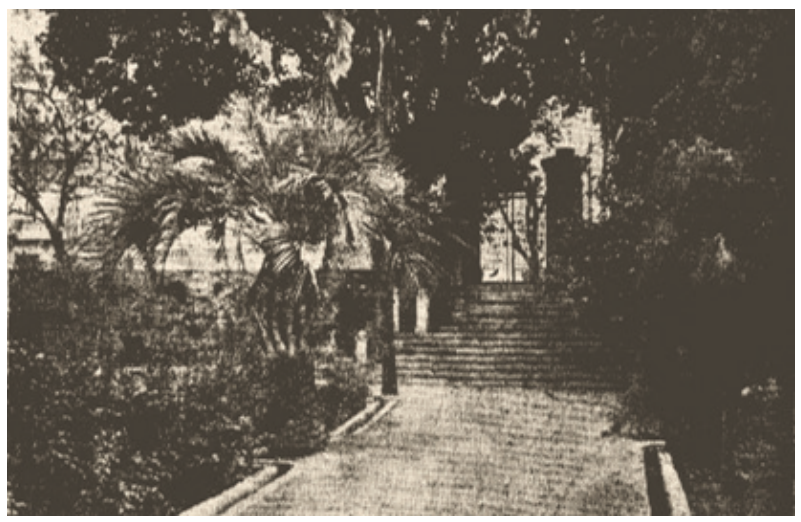

Figura 3. Fotografía de la puerta de acceso al Jardín Botánico y del interior en la que puede verse una especie de canaletas de riego en los márgenes de los parterres que recuerdan a los jardines de estilo andalusí (Vázquez, 1960, p. 6).

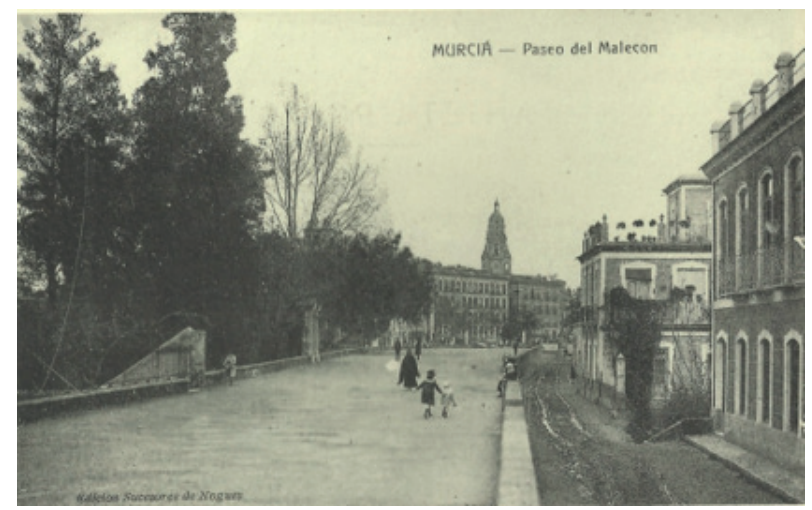

Figura 4. Vista del Paseo del Malecón y de árboles de gran porte como la Casuarina cunninghaniana y el Platanus orientalis. Postal editada por Sucesores de Nogués. Murcia.

\section{Deterioro y olvido}

Las Memorias del instituto murciano posteriores a 1911 muestran que no se hace mención a nuevas incorporaciones de material, salvo del micrográfico. La situación del Jardín fue deteriorándose hasta llegar a perder su función didáctica. Rafael Verdú explicaba en 1956 que el Jardín Botánico sufrió mucho durante la guerra, "ocupado por las Brigadas 
Internacionales primero, convertido en lago y piscina popular después, terminó convirtiéndose en un erial, donde aún, por milagro, vivían al acabar la contienda algunas de las plantas aclimatadas a fuerza de años y cuidados" (Verdú, 1956, p. 1). El profesor y exdirector del Instituto, Francisco Morote, comentaba que la ordenación y cuidado del Jardín en los años 40 estuvo a cargo de Ignacio Marín Robles y Rafael Verdú, administrativa y pedagógicamente responsables de su conservación y funcionamiento, profesores que se esforzaron en la catalogación y nomenclatura de las especies existentes. Se consiguieron logros muy plausibles pese a las inundaciones que propiciaban los desbordamientos del río Segura (Morote, 1987). Pese a los esfuerzos del profesorado, el Jardín Botánico siguió sufriendo el abandono hasta llegar a ser utilizado por el Ayuntamiento como lugar para instalar los pabellones de la feria de septiembre. Rafael Verdú informó al Ministerio sobre los hechos explicando que el Jardín pertenecía al Instituto y que las especies allí representadas se habían logrado gracias a los desvelos y cuidados del profesorado de Ciencias Naturales y Agricultura. Alegaba que "es un exponente de cultura que dice mucho en favor del buen nombre del Instituto e incluso de la población" (Verdú, 1956, p. 2). Finalmente el centro propuso que si el Ministerio decidiera ceder el Botánico, fuese "permutando con terrenos equivalentes al valor del mismo, para la construcción de un nuevo Instituto" (Verdú, 1956, p. 3). En una conferencia ofrecida en 1958 el profesor Verdú (1958) manifestaba que:

los 119 años transcurridos desde su fundación, a lo largo de los cuales el Instituto vertió su cariño, predilección y caudal en esta obra cultural que se salía un poco de sus aulas recoletas, no constituyen, por lo visto, suficiente ejecutoria de nobleza y propiedad para determinadas entidades, que haciendo caso omiso de ella pretenden arrebatárselo. Verdadera pena es que por el Estado no se le haya prestado en estos últimos años la más mínima atención. (p. 6.)

En 1970 se proyectó un nuevo jardín que englobaría parte de los terrenos del antiguo Jardín Botánico y los de los huertos aledaños al Paseo del Malecón, que de ahí en adelante se conocerá como Jardín del Malecón, construido en 1974. En 1985 se pensó en recuperarlo como jardín botánico dado que era el de mayor superficie de los existentes en la ciudad y con mayor número de especies. Se realizaron nuevas plantaciones que 
complementaban a los ejemplares históricos del Jardín Botánico y de los huertos. También se colocaron placas de metacrilato blanco con letras grabadas en negro, con los datos de cada una de las especies. Además se editó una guía del profesor y otra para el alumnado (Sánchez, 1989). Durante muchos años el mantenimiento de la colección botánica y el del propio jardín fueron decayendo paulatinamente llegando a un estado de semi-abandono, con la mayoría de placas identificativas rotas y muchas de las especies de la colección desaparecidas o en muy mal estado. A esta lamentable situación favoreció el hecho de que, año tras año, el jardín se ha ido adaptando como recinto ferial para las fiestas locales.

En la actualidad sobreviven algunos ejemplares antiguos recientemente inventariados (Marín, 2014). Uno de los más emblemáticos es una vieja sabina mora (Tetraclinis articulata), especie del Mediterráneo occidental distribuida principalmente por el norte de África. Sobre el mismo, el botánico Francisco de Paula Jiménez Munuera, en 1908 ${ }^{11}$, hace referencia por primera vez a los escasos ejemplares europeos de sabina mora que localizó silvestres en Cartagena, y añade lo siguiente: "En el Jardín Botánico del Instituto de Murcia hay también un magnífico ejemplar que no tendrá menos de 6 a 8 m" (Jiménez, 1908, p. 270).

La Asociación de Amigos del Jardín Botánico inició en 2012 un proyecto para reivindicar y proteger el legado de este espacio. Se solicitaron al Ayuntamiento dos parterres para realizar la plantación de especies autóctonas de la región de Murcia y otra de interés etnobotánico. De esta forma se pretendía completar el número de especies que albergaba el Jardín y dar a conocer a los visitantes la flora regional y mediterránea que hasta la fecha era minoritaria en el mismo. Para ayudar a la identificación el Ayuntamiento de Murcia facilitó carteles que se colocaron al lado de cada ejemplar con el nombre científico, el común y el de la familia a la que pertenece. Se han tratado de incorporar a la colección especies de especial interés botánico, entre las que destaca el garbancillo de Tallante (Astragalus nitidiflorus) del que se obtuvieron 67 frutos que fueron entregados al Proyecto LIFE Conservastratragalus-MU, para su conservación en el Banco de Germoplasma de la Universidad Politécnica de Cartagena, contribuyendo a la conservación de la especie, una de las razones de ser de un Jardín Botánico. También se han incorporado ejemplares de otras especies como la esparraguera del Mar Menor (As-

11 Agradecemos a José Antonio López Espinosa el interés y la información histórica aportada sobre este árbol. 
paragus macrorrhizus) y la jara de Cartagena (Cistus heterophyllus subsp. carthaginensis) aportadas por la Oficina de Impulso Socioeconómico del Medio Ambiente de la Región de Murcia.

El creciente interés por la conservación y estudio del patrimonio histórico-educativo convierte esta mirada al pasado del Jardín Botánico del Instituto de Murcia en un ejercicio que trata de rescatar para el presente cómo se utilizó este espacio educativo y las actividades de enseñanza que en él se realizaron, y fuerza a repensar el futuro para que sea posible un proceso de sensibilización para conservar nuestro patrimonio y hacer de él un lugar de memoria social e individual. Esa sensibilización pasa por conocer para comprender, comprender para valorar, valorar para cuidar, cuidar para conservar y conservar para transmitir (Fontal e lbáñez, 2015).

\section{Referencias}

Boletín Oficial de la Provincia de Murcia (1859). Gobierno de la provincia (11de noviembre de 1859).

Cánovas, F. (1891). Curso de Historia Natural. Murcia: Imprenta de "El Diario".

Carrasco, M. A., Millanes, A., Perea, D. y Rodríguez, J. (2001). Plantas de D. Ángel Guirao (?-1890) en el Herbario del Real Colegio Alfonso XII de San Lorenzo de El Escorial (Madrid, España). Botanica Complutensis, 25, 329-338.

Codorniu, R. (1909). Alianza de España con el árbol. Madrid: Imprenta Alemana.

Delgado, Ma A., López, J. D., Martínez, V. y Romera, Ma I. (2010). El gabinete de Física del Instituto de Lorca (1864-1883). Guía didáctica. Murcia: Consejería de Educación, Formación y Empleo.

Echegaray, J. (7 de agosto de 1847). Memoria premiada por la Real Sociedad Económica de Madrid sobre el sistema más conveniente de Silbicultura. Diario de Murcia, p. 2.

Fontal, O. y Ibáñez, A. (2015). Estrategias e instrumentos para la educación patrimonial en España. Educatio Siglo XXI, 33(1), 15-32.

Gaceta de Madrid (1845). Reglamento para la ejecución del plan de estudios decretado por S.M. en 17 de septiembre de 1845 (1 de noviembre de 1845).

Galdo, M. de (1856). Manual de Historia Natural. Madrid: José Rodríguez.

García, E. (2013). Los jardines botánicos como centros de difusión y conservación de Historia Natural: el caso del Real Jardín Botánico de Madrid. Museos y colecciones de Historia Natural. Investigación, educación y difusión. Memorias de la Real Sociedad Española de Historia Natural, 11, 27-40.

Gil, A. (1855). De la instrucción pública en España. Madrid: Imprenta del Colegio de Sordomudos, 3 t.

Harada-Giro (1 de octubre de 1921). La exposición regional de pintura y escultura. La Región Gráfica, p. 22. 
El Jardín Botánico del Instituto Provincial de Murcia: pasado, presente y futuro José Pedro Marín Murcia, José Damián López Martínez y Luisa López Banet

Hernández, F. (1983). El primer centro oficial de segunda enseñanza en Murcia. Murcia: Universidad de Murcia.

Hernández, P. (2009). La evolución de las Ciencias Naturales en la Segunda Enseñanza española. Cáceres: Universidad de Extremadura.

Instituto Provincial de Segunda Enseñanza de Murcia (1859). Memoria leída el $1^{\circ}$ de noviembre en la inauguración de 1859 a 1860. Murcia: Imprenta de Anselmo Arques.

- (1862). Memoria leída el 16 de setiembre en la inauguración del curso 1862 a 1863. Murcia: Imprenta de Anselmo Arques.

- (1882). Memoria leída en la solemne inauguración del curso académico de 1882 a 1883. Murcia: Tipografía de Anselmo Arques.

- (1884). Memoria leída en la solemne inauguración del curso académico de 1883 a 1884. Murcia: Tipografía de Anselmo Arques.

- (1887). Memoria leída en la solemne inauguración del curso académico de 1886 a 1887. Murcia: Tipografía de Anselmo Arques.

- (1889). Memoria leída en la solemne inauguración del curso académico de 1888 a 1889. Murcia: Tipografía de Anselmo Arques.

- (1890). Memoria leída en la solemne inauguración del curso académico de 1889 a 1890. Murcia: Tipografía de Anselmo Arques.

- (1891). Memoria leída en la solemne inauguración del curso académico de 1890 a 1891. Murcia: Tipografía de Anselmo Arques.

- (1892). Memoria leída en la solemne inauguración del curso académico de 1891 a 1892. Murcia: Tipografía de Anselmo Arques.

Instituto General y Técnico de Murcia (1907). Memoria leída en la solemne inauguración del curso académico de 1906 a 1907. Murcia: Impresores Sucesores de Nogués.

- (1908). Memoria leída en la solemne inauguración del curso académico de 1907 a 1908. Murcia: Impresores Sucesores de Nogués.

- (1909). Memoria leída en la solemne inauguración del curso académico de 1908 a 1909. Murcia: Imprenta Sucesores de Nogués.

- (1910). Memoria leída en la solemne inauguración del curso académico de 1909 a 1910. Murcia: Imprenta Sucesores de Nogués.

- (1912). Memoria leída en la solemne inauguración del curso académico 1912 a 1913. Murcia: Imprenta Sucesores de Nogués.

Jiménez, F. P. (1908). Plantas de Cartagena, adiciones y rectificaciones. Actas del Primer Congreso de Naturalistas Españoles, Zaragoza.

López, C. (2001). Ciencia y enseñanza en algunas instituciones docentes murcianas 1850-1936. Murcia: Servicio de Publicaciones de la Universidad de Murcia.

Marín, J. P. (2014). El material científico para la enseñanza de la botánica en la Región de Murcia (1837-1939) (tesis doctoral). Universidad de Murcia, Murcia.

Morote, F. (1987). Testimonio de profesores y alumnos. En R. Jiménez (Coord.) El Instituto Alfonso X el Sabio: 150 años de historia (pp. 341-347). Murcia: Editora Regional Murciana.

Museros, T. (1880). Lecciones de Agricultura elemental. Madrid: Agustín Jubera.

Peñaflor (9 de enero de 1900). Madrid al día. El árbol. (Las fiestas en La Unión). Las Provincias de Levante, p. 1. 
El Jardín Botánico del Instituto Provincial de Murcia: pasado, presente y futuro

José Pedro Marín Murcia, José Damián López Martínez y Luisa lópez Banet

Pereda, S. de (1864). Programa razonado de un curso de Historia Natural. Madrid: Imprenta de Alejandro Gómez Fuentenebro.

Ruiz, M. C. (1983). La Universidad Literaria de Murcia (1840). Monteagudo, 82, 5-17.

Sánchez, J. M. (1989). Guía del Jardín Botánico del Malecón. Murcia: Ayuntamiento de Murcia.

Sánchez, J. M. (2004). José Echegaray: entre la ciencia, el teatro y la política. Arbor, CLXXIX, 707-708, 601-688.

Segura, P. (1987). La época de fundación (1837-1857). En R. Jiménez (Coord.) El Instituto Alfonso X el Sabio: 150 años de historia (pp. 51-88). Murcia: Editora Regional Murciana.

Utande, M. (1964). Planes de estudio de Enseñanza Media. Madrid: Ministerio de Educación Nacional, Publicaciones de la Dirección General de Enseñanza Media.

Vázquez, P. (22 de agosto de 1960). El Botánico: lo que fue y lo que es. Hoja del Lunes, p. 6.

Verdú, R. (1956). Informe del Director del Instituto de la situación del Jardín Botánico. 15 de noviembre de 1956. Murcia: Instituto Nacional de Segunda enseñanza de Murcia. - (1958). Lo que el Instituto ha hecho por Murcia. Murcia: Instituto Alfonso X El Sabio.

Vergel, A. (16 de junio de 1929). Jardines y monumentos murcianos. Levante Agrario, p. 3

Vidal, J. A. y López, C. (1987). Cincuenta años de enseñanza de las ciencias (1860-1910). En R. Jiménez (Coord.) El Instituto Alfonso X el Sabio: 150 años de historia (253-287). Murcia: Editora Regional Murciana.

Viñao, A. (1986). El Colegio-Seminario de San Fulgencio: Ilustración, Liberalismo e Inquisición. Áreas. Revista Internacional de Ciencias Sociales, 6, 18-48.

- (2008). Escolarización, edificios y espacios escolares. CEE Participación Educativa, 7, 16-27.

— (2010). Memoria, patrimonio y educación. Educatio Siglo XXI, 28(2), 17-42.

\section{Agradecimientos}

Este trabajo se ha llevado a cabo con la ayuda concedida por el Ministerio de Economía y Competitividad al proyecto de investigación EDU2013-42040-P "Imagen y educación: marketing, comercialización, didáctica (España, siglo XX)". 